\title{
Representações dos profissionais da saúde pública sobre as práticas integrativas e complementares na Cidade de Viçosa-MG, Brasil
}

\author{
Representations of public health professionals on integration and complementary practices in
}

Viçosa-MG, Brazil

Representaciones de profesionales de salud pública sobre prácticas integrativas y complementarias em la Ciudad de Viçosa-MG, Brasil

Recebido: 13/11/2020 | Revisado: 19/11/2020 | Aceito: 19/04/2021 | Publicado: 02/05/2021

\author{
Marco Paulo Andrade \\ ORCID: https://orcid.org/0000-0002-3407-3422 \\ Universidade Federal de Viçosa, Brasil \\ E-mail: marco.paulo@ufv.br \\ Sheila Maria Doula \\ ORCID: https://orcid.org/0000-0003-0310-9055 \\ Universidade Federal de Viçosa, Brasil \\ E-mail: sheila@ufv.br \\ João Paulo Louzada Vieira \\ ORCID: https://orcid.org/0000-0002-9931-7248 \\ Universidade Federal de Juiz de Fora, Brasil \\ E-mail: joaopaulo.jplv@gmail.com \\ Isadora Moreira Ribeiro \\ ORCID: https://orcid.org/0000-0002-2622-4059 \\ Universidade Federal de Viçosa, Brasil \\ E-mail: isadora.moreiraribeiro@gmail.com
}

\begin{abstract}
Resumo
O artigo tem como objetivo analisar as representações de profissionais de saúde pública do município de Viçosa - MG acerca das Práticas Integrativas e Complementares (PICs). A metodologia é de natureza qualitativa. Partindo-se do histórico de institucionalização política dessas práticas, utiliza-se a Teoria das Representações Sociais para análise das entrevistas. Os resultados se organizam em dois eixos temáticos, os quais tratam do conhecimento e aceitação das práticas integrativas e da inserção das benzedeiras no SUS. Observa-se que os profissionais desconhecem a Política Nacional de Práticas Integrativas e Complementares, mas reconhecem as práticas por ela abrangidas. Conclui-se que a ineficiência na divulgação da política influencia as percepções sobre sua eficácia e possibilidade de serem executadas. Palavras-chave: Terapia complementar; Política de saúde; Sistema único de saúde.
\end{abstract}

\begin{abstract}
The present study aims to analyze the representations of public health professionals of the municipality of Viçosa MG on Integrative and Complementary Practices (referred in this article as PICs). The methodology applied in this research is qualitative. Based on the history of the political institutionalization of these practices, the Theory of Social Representations is used to analyze the interviews. The results are organized in two thematic axes, which deal with the knowledge and acceptance of the integrative practices and the insertion of the healers in the Health Unic System (referred in this article as SUS). It is observed that the professionals are not aware of the National Policy of Integrative and Complementary Practices, but recognize the practices covered by it. It is concluded that the inefficiency in the disclosure of the policy has influences in the perceptions about its effectiveness and possibility of being executed.
\end{abstract}

Keywords: Complementary therapies; Health policy; Unified health system.

\section{Resumen}

El artículo tiene como objetivo analizar las representaciones de los profesionales de la salud pública del municipio de Viçosa - MG sobre las Prácticas Integrativas y Complementarias (PIC). La metodología es de carácter cualitativo. A partir del histórico de institucionalización política de estas prácticas, se utiliza la Teoría de las Representaciones Sociales para analizar las entrevistas. Los resultados se organizan en dos ejes temáticos, que abordan el conocimiento y aceptación de prácticas integradoras y la inserción de los curanderos en el SUS. Se observa que los profesionales desconocen la Política Nacional de Prácticas Integrativas y Complementarias, pero reconocen las prácticas que abarca. Se concluye que la ineficiencia en la difusión de la política influye en las percepciones sobre su efectividad y la posibilidad de implementación.

Palabras clave: Terapia complementaria; Política de salud; Sistema único de salud. 


\section{Introdução}

Desde a década de 1970, vem se discutindo a importância das Práticas Integrativas e Complementares (PICs) de saúde. Por meio da declaração de Alma Ata, a Organização Mundial da Saúde - OMS criou o Programa de Medicina Tradicional $^{1}$, que tinha como finalidade incentivar os países a implementarem políticas públicas que integrassem a Medicina Tradicional Complementar/Alternativa em seus sistemas de saúde. A partir desta experiência, diversos outros acordos e propostas internacionais foram realizados, como o documento WHO Tradicional Medicine Strategy 2002-2005, que objetivava o desenvolvimento de políticas sobre o uso e acesso à medicina tradicional. O documento mais recente, WHO Tradicional Medicine Strategy 2014-2023, tem como foco apoiar os países membros para que aproveitem a contribuição da Medicina Tradicional na manutenção da saúde, promovam a atenção centrada nos indivíduos e regulamentem as práticas e os profissionais (Who, 2013).

No Brasil, a incorporação das práticas integrativas e complementares teve início a partir da criação do Sistema Único de Saúde (SUS), na década de 1980. No entanto, apenas no ano de 2006, em concordância com as recomendações da OMS, foi aprovada a Política Nacional de Práticas Integrativas e Complementares (PNPIC) no SUS (Brasil, 2006). A aprovação da PNPIC introduz o Brasil na vanguarda das Práticas Integrativas no sistema oficial de saúde em relação a outros países das Américas. Essa política assegura aos usuários do SUS o acesso à medicina tradicional chinesa/acupuntura, homeopatia, plantas medicinais e fitoterápicas, entre outras.

As ações da PNPIC preconizam o entendimento e a valorização da multi e interculturalidade por gestores e profissionais de saúde, considerando o sujeito, sua cultura e suas singularidades. Ressalta-se a importância de os profissionais da saúde respeitarem os valores e crenças dos pacientes, não impondo os seus conhecimentos como superiores, colaborando para a maior eficiência nos tratamentos (Leininger, 1991; Vasconcelos, 2001).

Em fevereiro de 2017, por meio da PNPIC, o Ministério da Saúde declarou oficialmente a importância das práticas populares de saúde, sendo publicado no Diário Oficial da União que o SUS contaria também com novas terapias, como meditação, arteterapia, reiki, musicoterapia, tratamento naturopático, tratamento osteopático e tratamento quiroprático (Brasil, 2017) $)^{2}$. De modo a capacitar e instruir os gestores públicos para a implementação da política, o Ministério da Saúde, em parceria com a Universidade Federal do Rio Grande do Norte e o Instituto Communitas para o Desenvolvimento Humano e Tecnológico, oferece gratuitamente o curso online de Gestão de Práticas Integrativas e Complementares (Brasil, 2017). Passados 10 anos desde sua implementação, os dados do Cadastro Nacional do Estabelecimento de Saúde - CNES mostram que as PICs se encontram distribuídas em 18,2\% dos estabelecimentos de saúde pública do território nacional, presentes em todas as capitais (Brasil, 2016).

As diretrizes da Política Nacional de Práticas Integrativas e Complementares apontam a importância de se institucionalizar essas práticas com o discurso de garantir a segurança de seus usuários. Uma das principais diretrizes afirma ser dever da Gestão Federal, Estadual e Municipal promoverem a divulgação das Práticas Integrativas e Complementares para sujeitos dos diversos extratos sociais. Os estados e municípios possuem certa autonomia na definição das suas políticas em saúde. Assim, as terapias são oferecidas no SUS por iniciativa local e recebem financiamento do Ministério da Saúde por meio do PAB - Piso de Atenção Básica (Brasil, 2017).

\footnotetext{
${ }^{1}$ Medicina tradicional definida pela WHO (2013) como: "It is the sum total of the knowledge, skills and practices based on the theories, beliefs and experiences to different cultures, whether explicable or not, used in the maintenance of health, as well as in the prevention, diagnosis, improvement or treatment of physical and mental illnesses".

${ }^{2}$ Para maiores detalhes consultar o Diário Oficial da União. Osteopatia, Quiropraxia, Reflexoterapia, Reiki, Shantala, Terapia Comunitária Integrativa e Yoga à Política Nacional de Práticas Integrativas e Complementares. Diário Oficial da União, 27 de março de 2017. Retrieved from http://pesquisa.in.gov.br/imprensa/jsp/visualiza/index.jsp?jornal=1\&pagina=68\&data=28/03/2017
} 
Ainda que a intenção das organizações e órgãos governamentais seja de sistematizar e institucionalizar essas outras formas de se fazer medicina, percebe-se um esforço em desenvolver um diálogo entre os saberes da tradição e os científicos. Neste sentido, algumas cidades brasileiras, como Florianópolis-SC e Rebouças-PR, vêm se destacando ao buscar uma articulação entre a medicina tradicional e a medicina científica, integrando benzedeiras e rezadeiras ao serviço público de saúde. Além de admitirem as benzedeiras nos Centro de Saúde da Família, algumas cidades aprovaram leis de reconhecimento das práticas de benzeção como um ofício tradicional da saúde popular, como é o caso de Rebouças e São João do Triunfo, ambas no Paraná (Brasil, 2012)

As benzedeiras combinam elementos místicos aos saberes da medicina popular (Oliveira, 1985). São habitualmente procuradas por membros das classes economicamente mais baixas, que, no geral, têm suas crenças ignoradas pelos profissionais da saúde (Boltanski, 2004). Além disso, o vocabulário médico se apresenta como um obstáculo para esses segmentos populares por exigir a compreensão da norma culta para o seu entendimento (Leininger, 1991; Boltanski, 2004).

Na cidade de Viçosa - Minas Gerais, lócus dessa pesquisa, as PICs foram aprovadas em 2009, sendo uma das suas diretrizes a divulgação dos benefícios dessas práticas (Viçosa, 2009). Porém, são poucas as referências em documentos oficiais, assim como em trabalhos acadêmicos, que avaliam os resultados alcançados nesta década de implementação da política, a fim de verificar as consequências para o sistema de saúde e para a população que acessa tais serviços. Neste sentido, é objetivo deste artigo analisar as representações de profissionais de saúde pública do município de Viçosa - MG acerca das Práticas Integrativas e Complementares (PICs).

\subsection{Teoria das Representações Sociais}

Nas interações sociais, as representações norteiam as condutas e as formas de se comunicar, influenciando, também, nos processos de transmissão dos conhecimentos e na permanente constituição das identidades (Jodelet, 2001). As representações são compreendidas como um saber elaborado no meio social, objetivando a construção de uma realidade compartilhada pelo grupo, instituindo uma ponte entre o imaginário e o mundo material (jodelet, 2001). Elas fornecem um ponto de referência pelo qual os indivíduos e os grupos se comunicam e interpretam as situações. Jodelet (2001, p.22) afirma que as representações sempre serão sobre algo ou sobre alguém e são um tipo de conhecimento elaborado e compartilhado socialmente. "Essa forma de conhecimento distingue-se do conhecimento científico por se tratar mais de uma visão de senso comum, mas que ainda assim é relevante para os estudos de interações sociais".

Neste sentido, o imaginário surge como expressão do pensamento e intenta dar sentido à realidade, e é por meio do imaginário e das relações em sociedade que as representações se difundem (Jodelet, 2001). Presentes no imaginário social, as representações são discursos sobre a realidade vivida, não sendo necessariamente a realidade, nem o elemento subjetivo e nem o objetivo dos atores (Jodelet, 2001).

A construção das representações é dependente das referências que o indivíduo possui, além de seus interesses pessoais e das influências da sociedade (Moscovici, 2012). Consequentemente, relacionadas às experiências vividas de quem lhes atribui sentido e, em função disso, serão inteligíveis e assimiladas pelos atores que compartilham os mesmos símbolos e o contexto de onde as representações emergem (Geertz, 2008).

Para além de dar sentido ao mundo, as representações norteiam as condutas que são próprias de cada sociedade. Assim, a teoria das representações sociais nos convida a entender os contextos onde as representações são criadas. Suas contribuições para este trabalho centram-se na possibilidade de discutir as representações que os profissionais da saúde, imersos nos preceitos da medicina científica em função de sua prática profissional, constroem sobre as Práticas Integrativas e Complementares. 
Compreender essas representações se faz necessário, tendo em vista que são os elementos presentes no imaginário desses atores que condicionarão as suas práticas profissionais e os seus comportamentos diante de uma política que caminha no sentido da integração dos diferentes saberes relacionados aos cuidados com a saúde humana. Essas representações podem ser responsáveis pelo sucesso ou insucesso da política, uma vez que a sua operacionalização se dá nessa esfera microssocial, dependente das ações desses indivíduos. Com efeito, pesquisas sobre as representações no campo da saúde têm demonstrado descompassos entre as políticas públicas e as representações sociais sobre as práticas de saúde (Saïas et al., 2014). Tais descompassos podem contribuir para a construção de uma realidade distorcida acerca da tentativa de implementação das práticas integrativas nesse setor, ocasionando diversos prejuízos para os usuários que optam por esses serviços.

\section{Metodologia}

Trata-se de um estudo de natureza qualitativa e de caráter exploratório (Lakatos \& Marconi, 2001). O campo empírico se constitui nas unidades de atenção básica à saúde da cidade de Viçosa, Zona da Mata Mineira. Foram realizadas entrevistas semiestruturadas (Lakatos \& Marconi, 2001) no período de abril a maio de 2018, com profissionais da saúde do Centro Estadual de Atenção Especializada, da Policlínica Municipal de Viçosa e da Unidade Santo Antônio I de Estratégia Saúde da Família.

Os entrevistados foram selecionados aleatoriamente, sendo abordados nas unidades de atendimento, apresentados aos objetivos da pesquisa e convidados a participar. Participaram das entrevistas 15 pessoas, sendo 10 mulheres e 5 homens, todos funcionários das Unidades Básicas de Saúde (UBSs). Todas as entrevistas foram conduzidas nas UBSs nos horários em que os participantes se encontravam disponíveis.

Com intuito de preservar as identidades dos informantes, iremos nos referir a eles como "Entrevista 1", "Entrevista 2" e assim por diante. As entrevistas foram transcritas e sistematizadas e as informações passaram por procedimentos de análise de conteúdo. Identificou-se as categorias que posteriormente foram agrupadas em dois eixos temáticos.

Em observância à resolução 466/12, do Conselho Nacional de Saúde, que diz respeito à participação de seres humanos em pesquisas, este trabalho foi submetido e aprovado pelo Comitê de Ética da Universidade Federal de Viçosa, sob o parecer 2.877.057.

\section{Resultados e Discussão}

Antes de adentrar na análise realizada a partir das narrativas dos entrevistados cabe mencionar que, no primeiro momento, ao serem indagados sobre a inserção de práticas integrativas e complementares nas Unidades Básicas de Saúde, a resposta obtida foi de desconhecimento sobre o funcionamento e, por vezes, sobre a existência dessa política. Assim, as entrevistas continham uma breve introdução apresentando a política e, através da exemplificação das práticas, os entrevistados puderam se situar diante da questão em relevo.

Dois eixos temáticos de discussão são apresentados. No primeiro, abordamos a política pública, englobando as informações que os entrevistados emitiram sobre ela, como divulgação, acesso, efetividade e custos. No segundo, tratamos das representações dos informantes sobre a inserção de benzedeiras no Sistema Único de Saúde - SUS.

\subsection{Conhecimento e aceitação da PNPIC}

Mesmo sendo profissionais da saúde pública, a maioria dos entrevistados (8) relatou desconhecer a Política Nacional de Práticas Integrativas e Complementares - PNPIC. Dentre eles, dois citaram a existência da Medicina Natural e da Fitoterapia no município de Viçosa nas Unidades Básicas de Saúde. Ambas são práticas inseridas na política que eles julgam desconhecer, ou seja, há uma percepção da prática, mas não um reconhecimento dela como uma política pública. 
Nas narrativas dos entrevistados observa-se que, mesmo aqueles que julgam conhecer a PNPIC e a compreendem como uma política importante, desconhecem que está se encontra implementada no município de Viçosa desde de 2009. Esse desconhecimento pode estar associado ao fato de que, embora a política esteja vigente há 9 anos, na prática são poucas as unidades básicas de saúde que fornecem esses serviços à população, que ocorre em ocasiões pontuais, geralmente ofertadas por terceiros. Dessa forma, as PICs fazem-se pouco presentes no cotidiano desses profissionais, o que sugere a falta de familiaridade e, consequentemente, de um repertório de elementos para a construção de representações.

Os quinze entrevistados não tinham conhecimento sobre a diversidade de alternativas medicinais contempladas pela política. Todos pediram exemplos do que seriam essas práticas para tornar compreensível o que é a PNPIC. Isso reafirma a ineficiência na divulgação e implementação dessa política e no acesso escasso às terapias integrativas.

Apenas os profissionais da Estratégia Saúde da Família - ESF relataram ter tido contato com terapias "nãoconvencionais", no caso o biomagnetismo. Contudo, esse contato se deu por meio de um projeto de extensão da Universidade Federal de Viçosa, não tendo relação com a política pública:

Nós tivemos uma terapia aqui com imã com uma aluna da UFV. Ela fez um tempo, 6 meses, fez aqui e no (bairro) Nova Viçosa e o pessoal gostou muito. Aí terminou o projeto e ela formou. Mas o pessoal gostou, quem estava sabendo e quem estava participando gostou. Dessa aí nós ficamos sabendo, mas do resto a gente não conhece, não (Entrevista 9).

Todos os entrevistados acreditam que a população desconhece os mecanismos pelos quais se tem acesso à política. Como as representações são o discurso da realidade vivenciada e dependem das referências dos sujeitos (Jodelet, 2001; Moscovici, 2012), é visível a relação que a experiência pressupõe na construção de uma representação. Assim, não se constitui de fato uma representação sobre a política, uma vez que ela não se objetiva a partir de um núcleo de referência. O que se observa são representações sobre as práticas institucionalizadas pela política, as quais se manifestam no cotidiano. Para eles, a ponte entre a política pública e a população são os profissionais da saúde; como estes desconhecem ou possuem poucas informações sobre como acessá-la, é esperado que população tenha pouco ou quase nenhum envolvimento com essa política.

Com intuito de saber qual a avaliação dos entrevistados a respeito da divulgação dessas políticas, perguntamos se os governos e a mídia realizavam uma veiculação efetiva. Todos os informantes argumentaram que não há uma divulgação eficaz e eficiente das PICs:

Acredito que não, porque se falasse na televisão, palestra, sei lá. Assim, nos lugares públicos eu não vi [...] (Entrevista 7).

Negativo, a população não. Informação são poucos que tem, muito pouco mesmo, porque se eles soubessem o direito que eles têm, entendeu? Mas o governo, ele não quer isso. Entendeu? Se todo mundo soubesse brigar por seus direitos seríamos um país, com certeza, muito melhor, mas infelizmente as políticas não são pregadas dessa forma [...] (Entrevista 2).

Depreende-se que quando o termo "política" é mencionado na narrativa a representação que ele suscita não é referente às práticas às quais essa política é destinada a cumprir, mas a um contexto mais abrangente da ineficiência dos serviços públicos em geral à falta de acesso do cidadão.

Acreditando que a população não tem conhecimento sobre a política pública, os entrevistados apontam a necessidade de maior divulgação. Além disso, defendem a PNPIC como um direito do cidadão e reconhecem os seus possíveis benefícios. 
Com efeito, para a implementação das políticas públicas de saúde é necessário o envolvimento de processos comunicacionais que propiciem a visibilidade pública e a disseminação de informações que permitam aos usuários do sistema de saúde compreender seu funcionamento (Espoti et al., 2016). Como evidenciado por Jodelet (2001), a comunicação é fundamental nos processos de emergência e circulação das representações. Se não há a divulgação, o que se inclui no que Moscovici (2012) delimita como sistemas de comunicação, responsáveis pela formação de opiniões e atitudes pelo público, as representações não podem se constituir. Os profissionais desconhecem a política e julgam que a população também desconhece. Contatações que se aproximam das observações de Habimorad, et al., (2020) ao argumentar que falta de conhecimento e instruções sobre as PICs se apresentam como entraves para o sua plena implementação e execução.

Ao dissertarem sobre o desconhecimento da população, surge nas falas das informantes a precariedade do SUS como empecilho para a adoção das práticas integrativas. Os Entrevistados 2, 5 e 6 apresentam que, na atual conjuntura, o SUS não possui recursos nem para custear os serviços básicos e que nesse quadro de carências a implementação da PNPIC seria impossível. Ademais, representam as PICs como terapias onerosas para o SUS, identificando o baixo orçamento e o repasse defasado para as USFs e hospitais como impedimento; ressaltam ainda que, havendo a possibilidade de contratação, os médicos seriam mais importantes para o serviço público. Como consequência, observa-se uma implícita hierarquização de saberes, valorizando os "saberes peritos" que são sustentados pela racionalidade científica, "excelência técnica" e profissional (Beck, et al., 2012). Os profissionais peritos colocam outras práticas como subalternas e não prioritárias na luta por recursos financeiros e humanos, ainda que existam estudos que apontam a eficiência das PICs em diversas situações, ao proporcionar o estabelecimento de hábitos saudáveis, melhorar a qualidade de vida e reduzir significativamente as internações hospitalares (Silva et al., 2015; Randow et al., 2016; Arar, et al. 2017).

Eu acho que ela (PICs) é cara, é melhor contratar médico do que contratar uma pessoa dessas, porque o médico tem certeza do que está fazendo (Entrevista 6).

Por conseguinte, o Entrevistado 6 ainda argumenta que "pessoas carentes" não conhecem a "medicina alternativa". Fica subentendido que pessoas de maior poder aquisitivo conhecem e têm acesso às práticas integrativas, enquanto os mais pobres não podem ter acesso pelo SUS a um tratamento tão caro.

(...) é cara porque tem essas coisas de acupuntura e tal. E a população de baixo nível não teria acesso de jeito nenhum, o preço de uma sessão de acupuntura vai lá em cima. É igual as (consultas médicas) particulares da vida (...) (Entrevista 6).

(...) igual você falou das cidades que tem benzedeira no SUS, isso é muito caro, entende? Pensa só, você vai ter que pagar a benzedeira e depois ainda comprar o remédio (Entrevistada 14).

Há uma incoerência entre a representação da benzeção como prática integrativa cara, tendo em vista que as benzedeiras não cobram pelos seus serviços e os entrevistados dispunham dessa informação. Parece haver um consenso na representação do desconhecido e do inacessível como coisas "caras", o que demonstra que no entorno do termo "SUS" se constitui uma representação que associa o serviço público à má qualidade, àquilo que não é monetizado. Possivelmente essas representações estão relacionadas ao fato de que, apesar da PNPIC, algumas dessas práticas não se encontram disponíveis em todas as cidades brasileiras, estando restritas a quem têm condições de pagar por profissionais particulares. Tais considerações vêm ao encontro do que foi observado no estudo de Rodrigues-Neto et al, (2009) sobre a homeopatia, em que as pessoas pobres não tinham acesso a esse tipo de tratamento, uma vez que não era disponibilizado no SUS. Esta é uma realidade 
vivenciada pelas camadas populares desde a implantação do SUS. A universalização do Sistema Único de Saúde, ao mesmo tempo em que permitiu a toda a população acesso aos serviços de saúde, ainda que precarizados ao longo dos anos, originou um processo de exclusão, em que as pessoas de maior poder aquisitivo migravam para o sistema privado (Cotta, 1998).

Entretanto, as despesas com as terapias complementares são, geralmente, mais baixas do que o da medicina alopática, principalmente porque os custos desta última estão constantemente aumentando (Ceolin, et al., 2009). As considerações de Ceolin vêm ao encontro do que discorre o Entrevistado 03. Ele argumenta que as práticas integrativas podem fazer com que se diminuam os gastos com o tratamento de doenças, uma vez que muitas dessas práticas se baseiam na prevenção. Além disso, o Entrevistado 1 expõe que a fitoterapia é uma alternativa viável e econômica para o tratamento de algumas doenças, comparando-a com os preços dos medicamentos alopáticos. Também o entrevistado 9 argumenta sobre a importância dessas práticas integrativas com o intuito de diminuir o alto consumo de medicamentos alopáticos.

Eu acho (bom). Porque evitaria, né? Muitos medicamentos, médicos.... Então eu acho que ajudaria. Muitas pessoas fazem, mas é por conta própria. ... Tanto a unidade básica quanto o hospital, para diminuir o uso de medicamentos, fazer o uso de fitoterápicos... Para deixar de usar os "Rivoltrils", essa enxurrada de medicamento que tem, né? Eu acho que seria bacana sim (...) (Entrevista 9).

Apesar de todos acreditarem na eficácia das PICs, os entrevistados 3, 5 e 6 apresentam algumas ressalvas e expressam que essas terapias devem ser utilizadas apenas em casos mais brandos, de preferência nas ESFs. Há também uma rejeição da ideia de terapias alternativas nos hospitais por representarem essas práticas como lentas e de uso contínuo, inapropriado para o ambiente hospitalar. Além disso, trazem em seus discursos que estas práticas podem apresentar um alto risco de contaminação para o ambiente hospitalar e que os pacientes dos hospitais necessitam de tratamentos mais rápidos por se encontrarem em situações mais graves. Entretanto, vários estudos demonstram que pacientes oncológicos têm grande afinidade com terapias "alternativas" (Elias e Alves, 2002; Spadacio e Barros, 2008; Ceolin et al, 2009; Pereira et al., 2015), em virtude destas reconhecerem o ser humano em sua integralidade.

(...) as terapias (PICs), e as benzeção são para tratar coisinhas bobas né (Entrevista 5).

(...) chazinho (fitoterapia) só funciona para dor de barriga (risos) (Entrevista 3).

(...) Eu acho esquisito ter uma pessoa de qualquer jeito dentro de um consultório, porque lá dentro a gente trabalha de jaleco, tem toda uma higienização, é tudo controlado, não dá pra ficar entrando qualquer pessoa, isso pode atrapalhar os profissionais. E tem também o problema de contaminação né, às vezes a pessoa não sabe como fazer a lavagem correta das mãos para entrar em algumas áreas do hospital e isso pode trazer problemas (Entrevista 6).

O conhecimento médico reforça a separação entre o corpo físico e espiritual, desconsiderando a subjetividade do indivíduo nos tratamentos, o que instituiu uma crise na medicina científica (Camargo, 2003; Ayres, 2004). Há uma narrativa médica estruturada a partir do discurso moderno, que coloca a medicina popular como incompatível com o espaço hospitalar, que é a materialização e a representação de um saber científico respaldado no método. Esse ideário modernizador propunha o rompimento entre a tradição e a modernidade (Beck, et al., 2012). Consequentemente, a medicina orientada pelo pensamento cartesiano conduz o seu projeto de cura pautado na separação entre corpo e alma, o que também justifica a subalternidade da medicina popular, uma vez que esta concebe o ser humano não só em sua perspectiva fisiológica, mas em sua perspectiva holística. Em adição, além da representação sobre a limpeza e assepsia, traduzida como a negação da presença de pessoas que 
não dominam as regras sanitárias necessárias ao ambiente hospitalar, emerge a polarização do tempo como norteadora dessas narrativas, o que se visualiza na ação dos medicamentos alopáticos em oposição ao das terapias complementares.

\subsection{Inserção de benzedeiras no Sistema Único de Saúde - SUS.}

Quando questionados se a presença de benzedeiras nas USFs e hospitais poderia atrair novos públicos, principalmente aquelas pessoas que têm resistência a procurar assistência médica, duas informantes assinalaram, pejorativamente, a possibilidade de atraírem pessoas idosas oriundas do meio rural. Ainda como parte do discurso da modernidade, a representação do rural como espaço de atraso surge em oposição às cidades como centros de um conhecimento supostamente legítimo.

(...) é coisa de gente lá de longe, lá de onde Judas perdeu as botas (Entrevista 11).

(...) benzedeira é coisa de gente velha, que mora lá na roça e não tem acesso à cidade (Entrevista 13).

Para estas informantes, a crença na benzedeira emerge como parte de um sistema cultural rudimentar e as pessoas que compartilham deste sistema seriam idosas com pouca instrução e se encontrariam isoladas em um rural arcaico e atrasado; por consequência, seriam adeptas das "crendices populares". Cotidianamente rotulamos os indivíduos, caracterizando o que julgamos ou não ser aceitável; a partir dessas representações, os estigmas serão construídos por meio das relações de poder (Goffman, 1988). Neste caso, o estigma surge da representação do profissional que conhece os mecanismos pelos quais a ciência opera em relação àqueles que desconhecem esses mecanismos e acreditam nos saberes da cultura popular.

Outro ponto de conflito sobre a aceitação ou não das práticas de benzeção no SUS nasce da dualidade entre ciência e conhecimento popular. O Entrevistado 3, por exemplo, afirma que para as benzedeiras atuarem no SUS, elas deveriam ser instrumentalizadas por médicos e enfermeiros. Nesse caso, a instituição médica é assumida como autenticadora do saber tradicional, conferindo-lhe validade por meio do método. Os entrevistados 5 e 6 argumentam que as benzedeiras não construíram procedimentos sistematizados e validados empiricamente quanto à eficácia de seus resultados:

Elas acreditam (as pessoas), mas não querem saber o fundamento não, e as benzedeiras não tem conhecimento sobre a saúde (Entrevista 6).

Eu acho que elas (benzedeiras) não têm conhecimento do que é. Eu acho que eles (população) acreditam, cada um tem sua crença, mas eles (benzedeiras) não têm nenhum aprofundamento teórico científico para estar contribuindo de verdade com a saúde (Entrevista 5).

Essa dualidade entre a ciência e o conhecimento popular configura-se em um problema quando "aprisiona ou suprime fluxos de sentidos importantes contidos nas contracorrentes, diversidades, resistências e singularidades que os consagrados padrões universais não contabilizam nem acolhem" (Almeida, p. 141, 2010). Com isso, muitos profissionais da saúde, médicos, entre outros, tratam seus valores e conhecimentos como superiores, desvalidando todo e qualquer conhecimento que não passe pelo crivo da ciência. Ao negar os saberes populares, os profissionais da saúde podem estar interferindo negativamente no tratamento de seus pacientes (Vasconcelos, 2001)

Os que acreditam nas possibilidades de desenvolvimento das PICs e na incorporação de benzedeiras nas Unidades Básicas de Saúde (UBSs) e hospitais, apontam o aspecto emocional e a subjetividade como fatores que influenciam na sua eficácia. Ao questionarmos o Entrevistado 4 sobre inclusão de benzedeiras no SUS, sua expressão facial mudou, ficou sorridente e rememorou como as benzedeiras são importantes no seu contexto familiar e pessoal. Disse que sua família é rural 
e que, além de serem adeptos da benzeção, possuem o hábito de utilizar plantas medicinais. Outros cinco entrevistados também trouxeram em suas narrativas a subjetividade influenciando na eficácia da benzeção:

(...) eu acho que é mais psicológico, acha que vai funcionar e funciona (Entrevista 7).

(...) muitas patologias clínicas que nós temos estão relacionadas ao psicológico da pessoa. Na maioria das vezes nenhum medicamento vai resolver, mas o conversar, até mesmo já foi comprovado que a parte espiritual tem uma fundamentação na melhoria de algumas... várias patologias clínicas. Então por que não? (Entrevista 2).

Se a gente tomar como base que muitas doenças são causadas pelo psicológico da pessoa. As pessoas ficam em um estado emocional que chega no ponto delas adoecerem por causa do estado emocional que elas ficam, uma benzedeira talvez poderia intervir nesse estado de ansiedade, depressão, até por uma crença mesmo que as pessoas tem de que está com mau-olhado e não deixar essas coisas chegarem a um nível de adoecimento e precisar de um tratamento médico (Entrevista 10).

Os entrevistados que julgam a benzeção como benéfica são favoráveis à presença das benzedeiras no SUS. Já aqueles que não compartilham da mesma crença demonstram grande desconfiança na inserção das mesmas em USFs e hospitais. Observa-se que a benzeção é representada como inofensiva, não havendo contraindicação, ao contrário da medicação alopática. Não obstante, percebe-se a polarização dos lugares de cura, traduzida na oposição entre hospitais e ambientes que são representados no imaginário dos entrevistados como específicos para a realização de práticas de benzeção.

Eu acho que podia ter sim, não faz mal pra ninguém né? Eu gosto de mais, de mais mesmo, me sinto até leve quando eu vou, muita gente que eu conheço vai também (Entrevistado 12).

Para mim é coisa de quem acredita, eu quando criança até já fui, mas eu não acredito nisso não, e acho que não precisa ter no SUS, é só ir na casa da benzedeira, né? (Entrevistado 14).

Percebe-se que aceitar ou não a benzeção está intimamente relacionado ao contexto sociocultural dos sujeitos (Boltanski, 2004). Logo, a legitimação da benzeção como eficaz e passível de ser inserida nos sistemas públicos de saúde se relaciona diretamente com as representações consensuais a seu respeito.

\section{Conclusão}

Percebemos a ineficiência na divulgação da Política Nacional de Práticas Integrativas e Complementares, uma vez que a maioria dos entrevistados, mesmo sendo profissionais atuantes no sistema de saúde pública, desconheciam essa política. Nesse sentido, na ausência de uma representação específica sobre as PICs, apresentam-se representações sobre o SUS, o ambiente hospitalar e a saúde pública de forma geral.

Ainda que existam estudos que validem a utilização das práticas integrativas no tratamento de doenças, nota-se a existência de afinidades eletivas, onde as experiências pessoais e a crença nessas práticas influenciam a percepção sobre sua eficácia. O mesmo foi constatado nas representações sobre a inserção de benzedeiras no SUS. Não obstante, a situação econômica brasileira, somada à imagem de um SUS precário, faz com que alguns entrevistados considerem a PNPIC como uma política supérflua, que não justifica gastos públicos com sua efetiva implementação. Porém, faz-se pertinente argumentar que as PICs possuem potencial profilático, e se executadas e implementadas com esse viés, podem reduzir significativamente 
os custos com a prevenção de doenças, ao conceber o ser humano em sua integralidade e estipular a reestruturação de alguns hábitos e costumes.

A dicotomia entre saber popular e científico e as relações de poder que se estabelecem figuram nas narrativas, emergindo a representação de que pessoas que procuram a benzeção são idosas, pouco instruídas e oriundas de um rural arcaico. Para além, percebe-se um discurso cientificista que tende a desqualificar outros saberes, ainda que estes se encontrem respaldados por uma política nacional. Aceitando que as representações construídas pelos profissionais da saúde sobre as PICs podem influenciar sua implementação e execução, cabe pensar estratégias de aceitação e implementação que reforcem a compreensão dessas práticas não como substitutas, mas como complementares, com aliás indica o próprio nome da política pública, e que estas devam ser desenvolvidas com o intuito de contribuir no processo de cura, compreendendo o indivíduo em sua integralidade. À vista disso, os resultados deste estudo apontam que é de suma importância que os profissionais da saúde se apropriem da PNPIC, de maneira a compreender do que se trata, qual sua importância e suas potencialidades.

\section{Agradecimentos}

O presente trabalho foi realizado com apoio do Conselho Nacional de Desenvolvimento Científico e Tecnológico (CNPq) e da Fundação de Amparo à Pesquisa de Minas Gerais (FAPEMIG).

\section{Referências}

Almeida, M. da. C. de. (2010). Complexidade, saberes científicos, saberes da tradição: Editora Livraria Fisica. 176 p.

Arar, F. C., Lopes, K. A. S., Alves, L. P., Narques, L. G. S., Braga, W. F. A., \& Ruckl, S. (2017). O uso da apiterapia no tratamento de câncer: uma revisão sistemática. Revista Apucarana-PR11(9): $73-80$.

Beck, U., Giddens, A., \& Lash, S. (2012) Modernização Reflexiva: Ed. UNESP. 336 p.

Boltanski, L. (2004). As classes sociais e o corpo. Ed. Graal. 180 p.

Brasil. (2016). Cadastro Nacional de Estabelecimentos de Saúde - CNES. cnes.datasus.gov.br/pages/downloads/arquivosBaseDados.jsp

Camargo, J., \& Kenneth, R. de. (2003). Biomedicina, Saber \& Ciência: uma abordagem crítica: Ed. Hucitec. 195 p.

Ceolin, T., Heck, R. M., Pereira, D. B., Martins A. R., Coimbra, V. C. C., \& Silveira D. S. S. (2009). A inserção das terapias complementares no sistema único de saúde visando o cuidado integral na assistência. Enfermería Global. (16), 1-9.

Elias, M. C., \& Alves, E. (2002). Medicina não-convencional: prevalência em pacientes oncológicos. Revista Brasileira de Cancerologia, 48(4), 523-532.

Espoti, C. D. D., Cavava, A. G., Côco, L. S. de A., Santos-Neto. E. T., \& Oliveira, A. E. (2016). As dimensões do acesso aos serviços de saúde bucal na mídia impressa. Saúde Soc. 25(1), 19-30.

Geertz, C. (2008). A Interpretação Das Culturas. Ed. LTC. 432 p.

Goffman, E. (1988) Estigma - Notas Sobre a Manipulação da Identidade Deteriorada. (4a ed.): LTC.

Habimorad P. H. L., Catarucci F. M., Bruno V. H., T., Silva I. B., Fernandes V. C., Demarzo M. M. P., Spagnuolo R. S., \& Patricio K. P. (2020). Potencialidades e fragilidades de implantação da Política Nacional de Práticas Integrativas e Complementares. Ciência \& Saúde Coletiva, 25(2), 395-405.

Jodelet, D. (2001) Representações Sociais: um domínio em expansão. In. Jodelet, D. (Org.). As representações sociais, 17-44.

Lakatos, E. M., \& Marconi, M. A. (2001) Metodologia do trabalho cientifico: procedimentos básicos, pesquisa bibliográfica, projeto e relatório, publicações e trabalhos científicos. (6a ed.): 228 p.

Leininger, M. (1991) Culture care diversity and universality: a theory of nursing. National langue for nursing press, $432 \mathrm{p}$.

Ministério da Cultura. Lei Municipal reconhece benzedeiras do Triunfo. 27/03/2012. www.cultura.gov.br/

Ministério da Saúde. Secretaria de Atenção à Saúde. Departamento de Atenção Básica. Política Nacional de Práticas Integrativas e Complementares no SUS PNPIC-SUS. Brasília: Ministério da Saúde, 2006. http://dab.saude.gov.br/portaldab/biblioteca.php?conteudo=publicacoes/pnpic

Moscovici, S. (2012). A psicanálise, sua imagem e seu público: Vozes. 456 p.

Pereira, D. T. S., Andrade, L. L, Agra, G., \& Costa, M. M. L. (2015). Condutas terapêuticas utilizadas no manejo da dor em oncologia. Rev Pesqui Cuid Fundam. 7(1):1883-1890. 
Research, Society and Development, v. 10, n.5, e17210510212, 2021

(CC BY 4.0) | ISSN 2525-3409 | DOI: http://dx.doi.org/10.33448/rsd-v10i5.10212

Portal Brasil. SUS passa a oferecer terapias alternativas para a população. pesquisa.in.gov.br/imprensa/jsp/visualiza/index.jsp?jornal=1\&pagina $=68 \&$ data $=28 / 03 / 2017$

Randow, R., Campos, K. F. C., Roquete, F. F., Silva, L. T. H., Duarte, V. E. S., \& Guerra, V. A. (2016). Periferização das práticas integrativas e complementares na atenção primária à saúde: desafios da implantação do liangong como prática de promoção à saúde. Revista Brasileira em Promoção da Saúde, 29:111-117.

Rodrigues-Neto, F. J., Figueiredo, M. F. S., \& Faria, A. A. (2009). Prevalence of the use of homeopathy by the population of Montes Claros, Minas Gerais, Brazil. Sao Paulo Med. J. 127(6), 329-334.

Saïas, T. Véron, L., Delawarde, C., \& Briffaul,t X. (2014). Prevention in mental health: social representations from french professionals. Health Sociology Review, 23(2), 159-164.

Silva, C. P. M., \& Rosado, A. F. B. (2017). Efeitos psicossociais da prática de yoga: uma revisão sistemática. Revista Iberoamericana de Psicología del Ejercicio y el Deporte, 12(2): 203-216.

Spadacio, C., \& Barros, N. F. de. (2008). Uso de medicinas alternativas e complementares por pacientes com câncer: revisão sistemática. Revista Saúde Pública. 42(1), 158-164, 2008.

Vasconcelos, E. M. (1996). A terapêutica médica e as práticas populares de saúde. Saúde em Debate.

Viçosa. (2009). Câmara Municipal de Viçosa. Projeto de Lei n. 1.935, de 06 de janeiro de 2009. Implanta as Terapias Naturais no âmbito da política municipal de saúde do Município de Viçosa, e dá outras providências. Política Municipal de Práticas Integrativas e Complementares. Viçosa, MG.

Who. (2013). World Health Organization. Tradicional Medicine Strategy 2014-2023. 73 p. 